\title{
Diferentes concepções da ciência e implicações para seu ensino
}

\section{Different conceptions of science and the implications for its teaching}

\author{
Yassuko Hosoume ${ }^{1}$ \\ Rebeca Vilas Boas Cardoso de Oliveira ${ }^{2}$
}

\begin{abstract}
RESUMO
Uma teoria científica é um corpo de conhecimento autocontido, com elementos estruturantes - as partes - que, numa lógica interna, compõem um todo articulado. As partes representam um conhecimento local, conceitual e profundo da teoria, enquanto o todo representa a espacialização, o racional, a formalização - um conhecimento em extensão. Numa teoria da Física, a escolha dos elementos que a compõem e a maneira como eles se articulam traduzem uma especial estrutura conceitual, resultando em um produto particular. Se a natureza deste produto é sincrônica e espacial, uma proposta de seu ensino implica seu desmonte epistemológico seguido de uma reconstrução didática, localizando e conceituando suas partes diacrônica e linearmente. A análise da Mecânica Clássica apresentada nos livros didáticos, aprovados no PNLD/2011, exemplifica as singularidades das desconstruções e reconstruções dessa teoria da Física, revelando as diferentes visões da mesma implícitas nessas obras propostas para seu ensino.
\end{abstract}

Palavras-chave: estrutura do conhecimento; conhecimento físico; mapa conceitual; livro didático.

${ }^{1}$ Doutora em Educação. Instituto de Física da Universidade de São Paulo e Pontifícia Universidade Católica de Minas Gerais, Brasil. E-mail: yhosoume@if.usp.br.

${ }^{2}$ Doutora em Educação. Instituto Federal de Educação, Ciência e Tecnologia de São Paulo, Brasil. E-mail: rebecavilasboas@gmail.com. 


\begin{abstract}
A scientific theory is a self-contained knowledge system with structuring elements - the parts - that, when considered through their internal logic, constitute an articulated total. The parts represent a local, conceptual and deep knowledge of the theory, whereas the total represents the utilization of space, the rational and the formalizing - meaning knowledge in extension. Inside a Physics theory, the choice of compound elements in combination with the way they mingle, reveal a specific conceptual structure, which results in a particular product. If this product has a synchronic and spatial nature, a proposal for its teaching will require an epistemological disassembling of its origin, followed by a pedagogical reconstruction, that focuses and classifies the parts in a diachronic and linear way. The analysis of the Classic Mechanics introduced by schoolbooks, duly approved by PNLD/2011, illustrates the particularities of the disassembling and reconstruction of this Physics theory, revealing the different aspects implied within this work suggested for its teaching.
\end{abstract}

Keywords: conceptual structure; physic knowledge; conceptual map; textbook.

\title{
A estrutura de uma teoria: um todo articulado
}

É natural do ser humano uma interpretação particular da natureza: ao olhar atentamente para o mundo, o homem já está teorizando (GOETHE apud GIANNOTTI, 1993). O senso comum, construído com a participação deste olhar, é uma interpretação primeira da natureza e possui uma certeza muito particular de como o mundo funciona, ainda que inconsciente. Por outro lado, a ciência é um conhecimento construído social e historicamente, com um outro olhar para a natureza, no qual estão a construção e também a reconstrução de teorias explicativas, com uso de uma linguagem e de um rigor muito específicos (ALVES, 1994; KNELLER, 1980). São construções elaboradas pelo homem e, portanto, "determinadas por visões de mundo, sendo influenciadas por pressões sociais, econômicas e políticas" (PEREIRA, 1995, p. 37).

A produção da ciência envolve em seu processo transformações na compreensão do comportamento da natureza, o que impossibilita o conhecimento científico de ser caracterizado como verdadeiro e acabado, embora as teorias elaboradas tenham se constituído "verdades históricas que têm fundamentado o homem da ciência para uma explicação dos fenômenos" (DELIZOICOV et al., 2002, p. 66). 
Uma teoria científica, resultado desse processo, se configura como "um produto sendo apresentado de modo organizado e acabado" (PEREIRA, 1995, p. 37), revelando seu caráter dual como processo e produto ao mesmo tempo. Em relação à Física, Pregnolatto afirma:

[...] enquanto processo de construção de conhecimento, a física tem uma história, que envolve embates entre ideias contrastantes desenvolvidas ao longo do tempo. Enquanto produto ela é organizada em complexas estruturas que constituem as teorias. (PREGNOLATTO, 1994, p. 2).

Os conceitos, as leis, os princípios, ou seja, as partes que compõem uma teoria da física, por exemplo, são articuladas por equações lógico-matemáticas e, por isso, é possível falar que uma teoria física é passível de uma estruturação lógica, ou seja, ela possui uma estrutura interna (ROBILOTTA, 1994; SALÉM, 1986).

O processo de construção de uma teoria é diacrônico, isto é, ele acontece ao longo de um intervalo de tempo. A teoria, no entanto, reflete uma fotografia datada: é como a comunidade científica vê o mundo naquele momento e, portanto, é sincrônica. Uma teoria elaborada apresenta uma estrutura conceitual, cuja construção também é um processo diacrônico, que envolve a significação e a articulação de suas partes compondo um todo.

Conhecer a teoria implica numa desconstrução, seja a partir das relações lógicas que articulam seus conceitos, seja a partir de seu aprofundamento conceitual. Esse processo de construção de significados não é exclusivamente racional, sendo também intuitivo, pois implica na escolha dos elementos (partes) que compõem a teoria, assim como nas articulações que eles estabelecem entre si para tecer uma estrutura conceitual.

As partes dessa estrutura conceitual são conhecimentos localizados, ocupando lugar bem definido. É possível dizer que as partes da teoria, justamente por serem localizadas, são conhecimentos do tipo tempo, isto é, são conhecimentos profundos: a profundidade requer a apropriação do saber, é ter consciência da parte, é um conhecimento sensorial, que aproxima, que abstrai, imagina; é um saber-sentir - se sente que sabe (ROBILOTTA, 1994).

As articulações entre as partes de uma teoria, ao tecerem a estrutura, compõem um todo, um conhecimento global. O conhecimento local, quando articulado, precisa de mais de uma dimensão, tornando-se um conhecimento do tipo espaço, que permite sua extensão: o saber em extensão significa ter a estrutura formada, racionalizada, com suas partes articuladas por relações lógicas. É necessário um jogo entre sentimento e pensamento, entre a intuição e a razão: 
Imaginação, ou seja, a capacidade de destacar a imagem concreta, imediata e presente do objeto ou do ato, e fazê-la existir à parte, por si, enquanto imagem apenas, no âmbito do pensamento. Quando isso se dá, a imagem, criada a princípio pela percepção sensível de um objeto ou de um fato definido, com o qual o indivíduo se defronta, se despoja das notas acidentais, particularizadas, inessenciais do objeto ou do fenômeno, para representá-lo em caráter essencial, generalizado, abstrato, universal, na condição de verdadeira ideia. [...] A imaginação, valendo-se agora de ideias abstratas, universais, dispensa a presença sensível da realidade, e se torna capaz de explorá-la, indiretamente, na esfera da representação subjetiva. (PINTO, 1979, p. 101)

Esse jogo dialético entre parte-local e todo-global é uma característica da estrutura de uma teoria física: ao mesmo tempo em que as partes (conhecimento local) compõem e dão sustentação ao todo (conhecimento global), o todo articulado dá significado às suas partes: a teoria é autocontida (SALÉM, 1986). Essa construção de significado, que é racional e, ao mesmo tempo, intuitiva, faz com que o todo seja maior que a soma das partes, ao mesmo tempo em que as partes, justamente por comporem o todo, são ressignificadas e, portanto, coexistem articuladas (SALÉM, 1986; KNELLER, 1980).

A teoria física carrega todas essas dualidades, ou seja, os "dois lados da moeda" coexistem, mas não os vemos simultaneamente: o conhecimento se manifesta sempre numa dialética entre parte-todo, local-global, tempo-espaço, profundidade-extensão, razão-intuição, pensamento-sentimento, como expressou Pereira na Figura 1.

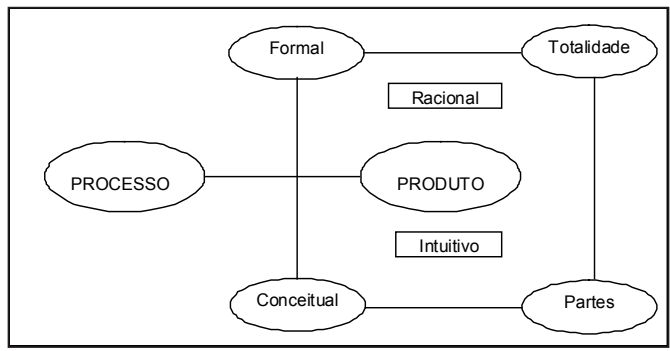

Figura 1 - Representação da relação processo-produto de uma estruturação. Fonte: PEREIRA, 1995, p. 68. 


\section{Uma representação da teoria: mapa conceitual}

Cada indivíduo, em seu processo particular de construção de conhecimento, tece uma estrutura sua da teoria, resultado desse seu processo de significação, e a maneira como a teoria é estruturada reflete, portanto, aquilo que se pensa sobre o assunto, a consciência do indivíduo sobre esse conhecimento.

Assim, conhecer envolve uma particular desconstrução do conhecimento científico e também uma particular reconstrução desse conhecimento quando ressignificado. Dessa forma, a definição dos elementos que sustentam uma teoria, assim como as relações estabelecidas entre eles, reflete as diferentes possibilidades de interpretação desse corpo de conhecimento.

Um mapa conceitual é a estrutura "coisificada", "reificada". Um mapa é a representação do objeto, no caso, a teoria. Mapear um conhecimento exige a realização da ideia, exige consciência e crença naquele conhecimento adquirido. Um mapa conceitual é, portanto, individual, apesar de representar uma teoria: é ao mesmo tempo objetivo e subjetivo, pois representa subjetivamente um conhecimento científico que é objetivo.

Construir um mapa exige uma aproximação-distanciada e um distanciamento-aproximado do conhecimento (ROBILOTTA, 1994; SALÉM, 1986). O processo de construção de significado, isto é, o conhecimento do objeto, exige que se chegue tão perto (conhecimento profundo) que permite criar a imagem concreta, ainda que com distanciamento. Ou seja, sabe-se quais elementos compõem a teoria, sabe-se alocá-los num mapa e cada um tem seu lugar próprio. No entanto, ao mesmo tempo, é o distanciamento do objeto que permite a articulação deste conhecimento, sua espacialização, estruturada num mapa. O mapa permite um ir e vir eternos entre os elementos da teoria, que são ligados por linhas lógicas. As linhas lógicas são sempre fechadas, ou seja, uma linha não se "perde" no mapa. Assim, percebem-se vários caminhos possíveis para se chegar a um conceito. $\mathrm{O}$ conceito é, então, uma intersecção de caminhos (SALÉM, 1986).

O mapa, ou seja, a "coisificação da teoria", possibilita sua manipulação. Nele os elementos aparecem unidos por uma linha, representando as relações matemáticas que existem entre as partes da teoria; não possuem setas indicativas e a ausência do sentido indica que o caminho a ser percorrido dentro da teoria, ou seja, a leitura do mapa, também não é único, está sujeito ao conhecimento/ visão que cada um tem do assunto.

No mapa conceitual, é possível também perceber a dualidade entre objetos e suas relações: o objeto (ou a parte) é concretizado na medida em que o 
feixe de relações que o constitui torna-se mais complexo (MACHADO, 1999), reforçando a ideia da estrutura autocontida de uma teoria física.

Mesmo não sendo único, como o mapa conceitual representa uma teoria da física, é possível reconhecer esse conhecimento em suas partes e articulações. Por exemplo, para construir um mapa da mecânica clássica, é preciso não apenas conhecer os elementos que compõem essa teoria, sendo necessário também saber/ decidir que lugares ocupam nessa estrutura de conhecimento, isto é, saber relacioná-los internamente, articulá-los para compor um todo coerente, harmônico.

O conhecimento da teoria envolve sua desconstrução, possibilitando uma reconstrução particular, que pode ser representada num mapa conceitual. A consciência desse mapa é importante principalmente quando se pretende ensinar essa teoria, pois uma proposta de seu ensino culminará na definição/ eleição dos elementos que serão apresentados, assim como nas possibilidades de relacioná-los. O ensino de uma teoria, portanto, implica a desconstrução do conhecimento estruturado de seu professor, que é o responsável por traduzir ao aprendiz uma leitura possível desse conhecimento.

\section{Um mapa conceitual para a teoria da mecânica clássica}

A mecânica clássica pode ser vista sob diferentes ângulos: um, newtoniano, centrando atenção às três leis de Newton, portanto, ao conceito de força, e outro, lagrangeano, com atenção às leis de conservação. No entanto, por trás desses dois olhares diferentes, encontram-se as leis de simetria, impondo algumas propriedades do espaço e do tempo, que consolidam a teoria.

Segundo POINCARÉ (1995, p. 7), “os espaços da matemática apenas têm realidade quando inseridos numa teoria Física". Na mecânica clássica, o espaço deve ser euclidiano, absoluto, que não se contrai. O espaço é homogêneo, implicando uma simetria de translação; espaço é isotrópico, preservando a simetria de rotação. O tempo absoluto garante uma simetria no próprio tempo na sua uniformidade. Seguindo a indagação de FEYNMAN et al. (1997): com uma propriedade de simetria, que fenômeno físico se constata? Nussenzveig afirma que "as leis de conservação estão ligadas a propriedades de simetria de sistemas físicos. Um sistema tem uma propriedade de simetria quando não se altera ao efetuarmos nele uma operação correspondente a essa simetria" (NUSSENZVEIG, 1985, p. 391).

Com a consideração de espaço e tempo absolutos, enunciam-se as três leis de Newton: a lei da inércia, a lei fundamental e a lei da ação e reação. As 
leis de Newton "não existem" separadamente, uma implica a outra. A mecânica newtoniana vale para referenciais inerciais, tem domínio não relativístico e macroscópico e se configura no espaço euclidiano, que abriga as leis de simetria.

Considerando a uniformidade temporal, ou seja, que o sistema será o mesmo (simétrico) se repetida a experiência em outro horário com preservação das condições iniciais, então, há conservação da energia mecânica total do sistema. Considerando a homogeneidade espacial, se o sistema não sofrer alteração se transladado como um todo, então a função energia potencial, que depende apenas da posição, trará a lei de conservação do momento linear. Quanto à isotropia espacial, ou seja, se o sistema não mudar quando girado como um todo, então, como no caso linear, haverá a conservação do momento angular. As leis de conservação estão ligadas às leis de simetrias de um sistema físico. São leis gerais, que valem tanto para sistemas macro quanto para sistemas micro.

Ou seja, da uniformidade do tempo e da homogeneidade e isotropia do espaço, isto é, das leis de simetria, têm-se as leis de conservação. Das leis de Newton também se chega às leis de conservação, porém com as imposições: de que apenas forças internas estejam atuando sobre o sistema, no caso da conservação do momento linear; de que as forças internas de interação entre os corpos sejam forças centrais, para a conservação do momento angular; e de que as forças sejam conservativas, para a conservação da energia.

Essas considerações feitas sobre a teoria são possíveis pelas linhas lógicas que articulam suas partes, exemplificando que é possível trilhar diferentes caminhos entre elas. E cada construção particular, feita de forma racional e intuitiva, permitirá definir caminhos também particulares no processo de significação.

Para a construção do mapa conceitual da mecânica clássica, foi tomado como referência o livro Curso de Física Básica - 1 - Mecânica (NUSSENZVEIG, 1985), escrito para a disciplina Física I da graduação em Ciências Exatas, portanto, escrito para cursos de formação básica, o que inclui a formação de professores de Física. Nussenzveig aborda a teoria da mecânica de forma bastante profunda, dispensando atenção especial a detalhes da teoria, como as leis de simetria e suas relações com as leis de conservação e leis de Newton.

A construção do mapa foi possível na medida em que os objetos da mecânica eram ressignificados. A primeira preocupação era entender quais elementos fariam parte desta estrutura; aos poucos, as articulações entre as partes foram estabelecidas, fortalecendo sua compreensão mais profunda, ao mesmo tempo em que garantia sua localização no mapa. O mapa construído tem as leis de Newton e as leis de conservação como coisas centrais (ou fundamentais) da teoria; desses conceitos "partem", e também "chegam", os outros elementos da teoria: é a articulação desses elementos que sustenta a teoria de forma harmônica. Essa leitura é apresentada pelo mapa conceitual da mecânica clássica da Figura 2. 


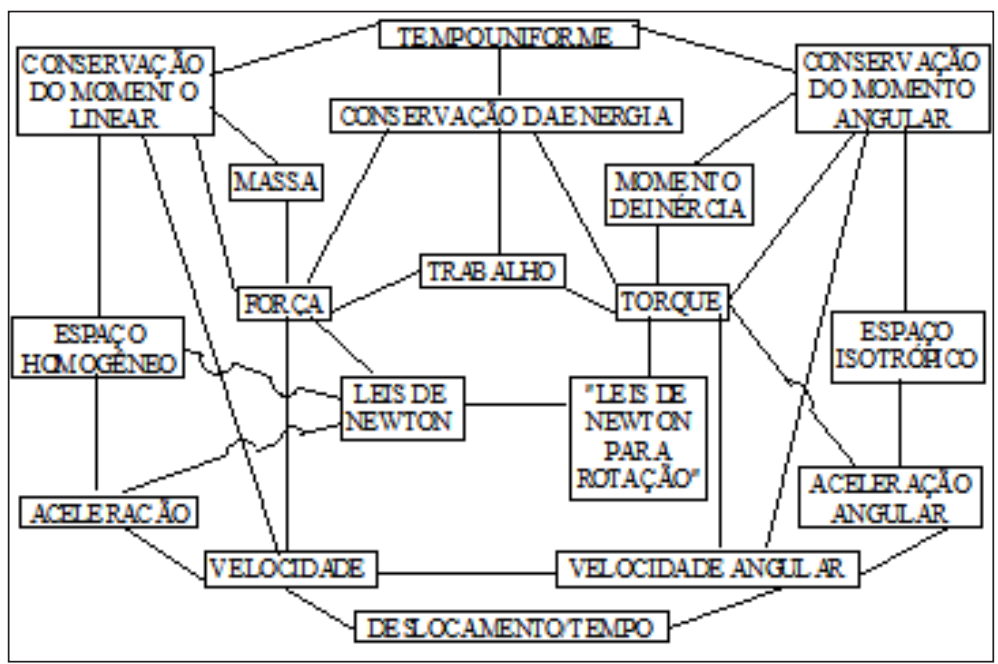

Figura 2 - Um mapa conceitual para a mecânica clássica.

Fonte: OLIVEIRA, 1999, p. 44.

Neste mapa, as simetrias, que configuram o espaço e o tempo, sustentam as leis de conservação e as leis de Newton. O elemento tempo uniforme aparece no alto e no centro do mapa, articulando-se com a translação e a rotação, dividindo o mapa e colocando seus respectivos elementos em lados distintos, ligados respectivamente por conservação do momento linear e conservação do momento angular.

Além de representar a translação e a rotação em lados distintos, buscou-se simetria na representação dos conteúdos da translação e da rotação no mapa. A massa, inercial, invariante, é um elemento importante no mapa, já que, articulada com espaço e tempo, dá sustentação à teoria. Foram inseridos os elementos com os nomes momento de inércia e "Leis de Newton para rotação", associando-os ao torque, que aparece não apenas para garantir a simetria do mapa, mas pela conservação do momento angular e da energia nas rotações. Além disso, sempre se faz uma analogia entre a rotação e a translação. Na parte inferior e ao centro do mapa, ficou o elemento deslocamento/tempo e, a partir dele, foram alocados os conceitos que descrevem os movimentos linear e angular.

Não existem setas que indiquem caminhos ou sequências de desenvolvimento da teoria, pois se trata de um mapa para a teoria estruturada, cabendo, portanto, a cada um escolher o caminho a ser percorrido, que exponha ou componha o seu conhecimento. Sendo assim, qualquer trajetória pode ser feita, seja para aprender, seja para estudar, seja para ensinar a teoria. Mais importante 
que conhecer os elementos que fazem parte deste mapa é conhecer as relações que estes estabelecem entre si, ou melhor, é conseguir articulá-los, porque são essas articulações que permitem a espacialização do conhecimento quando se eliminam as setas indicativas do caminho feito. Quando se caminha "livremente" pela teoria, quando se percebe que ir e vir não oferecem obstáculos, então, se conhece a teoria.

\section{A mecânica clássica dos livros didáticos para o Ensino Médio}

O conteúdo da Física é muito extenso. E as teorias são bastante complexas, exigindo certo grau de abstração do estudante, qualquer que seja o nível de ensino. Assim, mais importante que fornecer as peças de um quebra-cabeça, é importante garantir meios para a composição deste quadro (todo). Driblando a questão sobre que conteúdo ensinar na escola média, mesmo restringindo a Física à mecânica clássica, é grande a quantidade de "coisas" (ou itens) que se pretende apresentar ao aluno.

Se teoria é um conhecimento estruturado, ou seja, se seus conceitos se articulam para compor um todo, mais importante parece ser garantir a construção dos feixes de relações entre seus objetos, garantindo sua simplificação na construção de seus significados. Esta articulação dos conceitos dentro de uma teoria é o que fortalece a estrutura conceitual, o modelo teórico elaborado.

Uma proposta de ensino explicita claramente a linearização da teoria feita pelo seu autor, uma desconstrução particular. Ou seja, o autor tem uma concepção da teoria, construída a partir da significação particular de seu processo de construção do conhecimento. Trilhando caminhos diversos pelas partes, ele compõe um todo, que agora precisa ser novamente linearizado, desconstruído, ao se tornar uma proposta de ensino, numa reconstrução didática. Somam-se a isso leituras particulares do autor sobre a natureza deste conhecimento, sobre o significado da Física na escola, sobre vestibular, sobre ENEM ${ }^{3}$, sobre pré-requisito, sobre competências a serem promovidas, entre tantas outras questões.

Para exemplificar as reconstruções didáticas que são efetuadas no Ensino Médio, foram analisados livros didáticos tendo como pressuposto que os mesmos orientam a prática do professor em sala de aula (APPLE, 1995; LAJOLO, 1996), que indicam os conteúdos educativos que devem ser transmitidos às

\footnotetext{
${ }^{3}$ Exame Nacional do Ensino Médio.
} 
novas gerações (CHOPPIN, 2004), tornando-se assim o currículo real da escola na perspectiva de GOODSON (1995). Para a pesquisa, foram escolhidas as dez coleções de livros de Física indicadas pelo $\mathrm{PNLD}^{4} / 2011$, pela sua credibilidade e abrangência e por serem avaliadas e distribuídas pelo $\mathrm{MEC}^{5}$ para as escolas públicas em nível nacional, atingindo a ordem de 7.000.000 de estudantes.

As reconstruções da mecânica propostas para a educação média variam desde a quantidade de conceitos organizados, as escolhas dos elementos ou as relações básicas que sustentam a estrutura do conhecimento, até as relações que são estabelecidas entre os conteúdos. As dez coleções analisadas se distribuem ao longo de três reconstruções mais significativas: a primeira, a mais simples, representada pelo mapa 1, envolve poucos elementos e pouca articulação interna; a segunda, representada pelo mapa 2, amplia o número de elementos conceituais, com novas articulações entre estes; e a terceira, representada pelo mapa 3 , apresentando os mesmos elementos do mapa 2, diferentemente articulados. Embora as contextualizações e as articulações pedagógicas sejam diferentes, principalmente nas quantidades de situações do cotidiano, nos textos históricos inseridos e/ou atividades experimentais propostas, a reconstrução dos conteúdos da mecânica representada pelo mapa 1 é a mais frequente nas coleções analisadas.

Nesses mapas, os conteúdos escolhidos na reconstrução estão representados por retângulos sombreados de cinza; os hachureados representam os elementos a partir dos quais se propõem novos conteúdos; as linhas têm setas que indicam o caminho utilizado para articulação dos conceitos, sendo diferenciadas no traço para indicar momentos diferentes para o desenvolvimento da teoria.

\section{Reconstrução 1}

Nessa reconstrução (Figura 3 - Mapa 1), iniciada pela Cinemática, as grandezas deslocamento/tempo, velocidade e aceleração e suas relações são estudadas exaustivamente na descrição dos chamados MRU, MRUV e MCU6 tendo como ponto de partida a definição de deslocamento no tempo. Segue com a Dinâmica, partindo da grandeza força, que leva às Leis de Newton e a outros conceitos que se pretende desenvolver: o primeiro é o trabalho e, deste, chega-se

${ }^{4}$ Programa Nacional do Livro Didático.

${ }^{5}$ Ministério da Educação.

${ }^{6}$ Movimento retilíneo uniforme, movimento retilíneo uniformemente variado e movimento circular uniforme. 


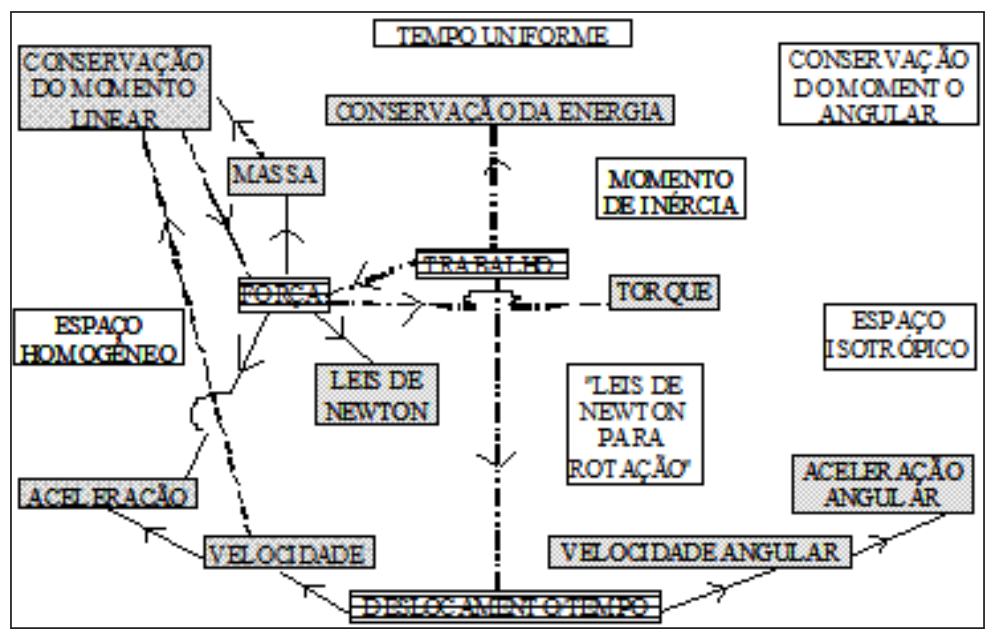

Figura 3 - Mapa 1.

à energia, seguida de sua conservação (conservação de energia); posteriormente, retoma a grandeza força para chegar à quantidade de movimento pela definição de impulso e a seguir chegar à conservação do momento linear. Após a conservação da energia e da quantidade de movimento, tem-se um pouco de gravitação universal. A Estática explora a ideia da força resultante e do torque. Observa-se que muitas linhas saem do elemento força, indicando sua importância nessa estruturação. Observa-se também que as linhas chegam às leis de conservação do momento linear e da energia. A mecânica das rotações não é desenvolvida, por isso a ausência total de linhas neste lado do mapa, embora as propriedades vetoriais tenham sido tratadas em muitas páginas do livro.

\section{Reconstrução 2}

Nesta reconstrução, representada no Mapa 2 (Figura 4), o início é semelhante à anterior, começando pela Cinemática, com a discussão do tempo/ deslocamento. A Dinâmica tem seu início em dois elementos: a força, que leva às leis de Newton e à conservação da energia, trazendo à discussão dos tipos de energia, seguida do desenvolvimento do elemento trabalho e potência. A hidrostática e as máquinas simples (estática) vêm no bojo da discussão das leis de Newton. A conservação do momento linear vem da relação dela com as leis 
de Newton e o desenvolvimento deste conteúdo parte da definição de momento linear a partir da relação massa e velocidade. A mecânica rotacional tem início com a definição do momento de inércia que, multiplicado pela velocidade angular, leva ao momento angular e sua conservação, e seu desenvolvimento se restringe à situação de torque nulo. Percebe-se que no Mapa 2 (Figura 4) a força ainda é o elemento que concentra o maior número de linhas, sendo ponto de partida para articulações feitas. A conservação do momento linear ainda é ponto de chegada das linhas, mas a conservação da energia apresenta-se como ponto de partida para o tratamento de alguns conceitos.

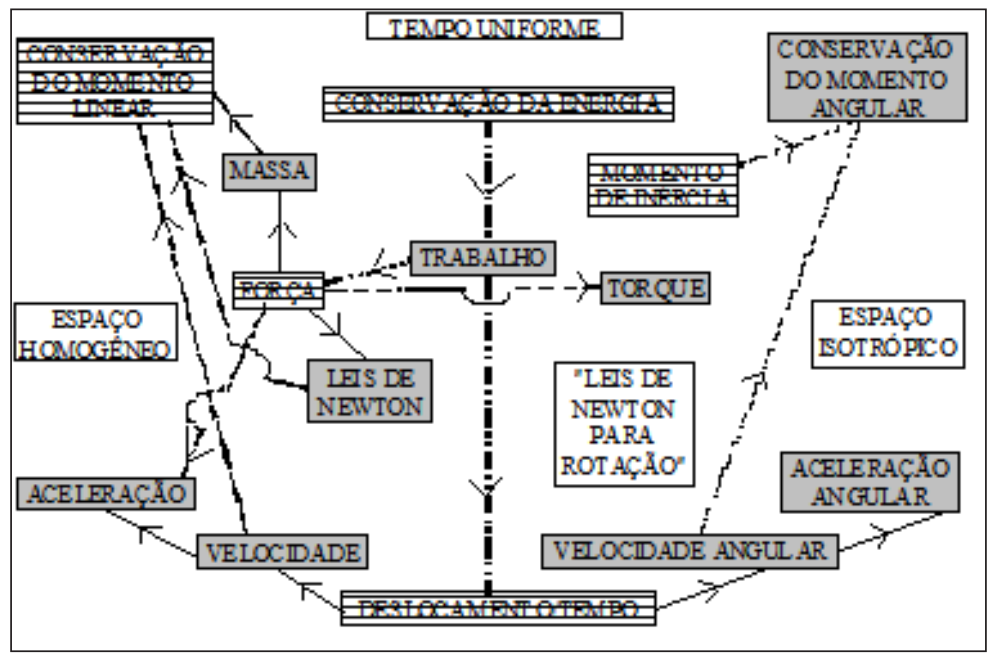

Figura 4 - Mapa 2.

\section{Reconstrução 3}

A reconstrução representada pelo Mapa 3 (Figura 5) começa com a conservação da energia a partir de um estudo geral de seus tipos e a energia mecânica é abordada levando à definição de trabalho. A conservação do movimento linear é o segundo ponto de partida e é apresentada como sendo a outra lei fundamental da Mecânica. A partir dela se chega à definição de força e se estabelece a sua relação com as leis de Newton, seguindo-se a identificação da aceleração. Os elementos da Cinemática, como deslocamento, velocidade e aceleração, são tratados no interior da Dinâmica, não sendo pontos de partida. A mecânica das 
rotações é iniciada com a lei de conservação do momento angular, que leva à definição de momento de inércia e de momento angular. Nessa reconstrução, são tratadas situações nas quais o torque está presente como responsável pela variação do momento angular. As linhas traçadas sem setas representam uma correspondência feita entre elementos da translação e da rotação. Nesta reconstrução, as três leis básicas da Mecânica (leis de conservação) são pontos de partida para o desenvolvimento dos conceitos.

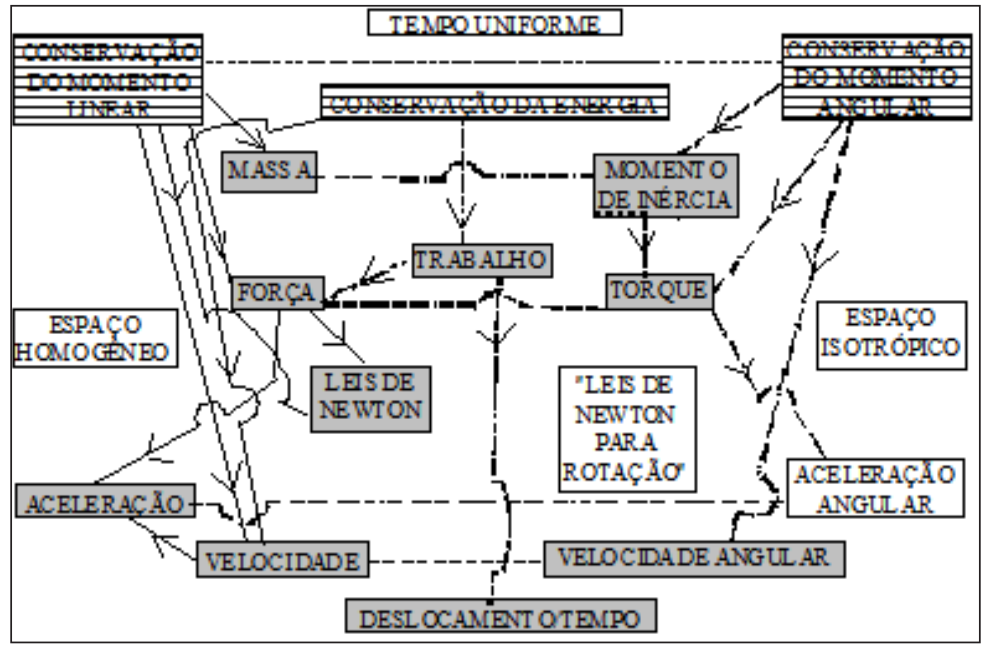

Figura 5 - Mapa 3.

Os pressupostos básicos da Mecânica, tempo uniforme e espaço homogêneo e isotrópico, que embasam as leis de conservação, não comparecem em nenhum dos três mapas.

\section{Conclusões e considerações}

As reconstruções representadas pelos três mapas permitem inferir que o ensino proposto em cada uma delas leva a diferentes compreensões da Mecânica. Na reconstrução representada pelo Mapa 1, a Mecânica é o estudo das descrições dos movimentos e das forças que são as causas dos movimentos. As leis de conservação da quantidade de movimento e da energia são compreendidas como consequências da atuação de forças através do impulso e do 
trabalho, respectivamente. Nesta reconstrução, no núcleo básico da Mecânica está o elemento força.

Na representação do Mapa 2, além da descrição dos movimentos, a Mecânica se constitui sobre dois núcleos básicos: a força e a conservação da energia. $\mathrm{O}$ primeiro se situa na perspectiva semelhante à do mapa anterior, levando às conservações da quantidade de movimento linear e angular como análise de forças em situações particulares. A conservação de energia é um ponto de partida para a análise de situações que envolvem vários tipos de força através do trabalho realizado por ela, constituindo-se um segundo núcleo básico.

Na representação do Mapa 3, a descrição dos movimentos (Cinemática) é apresentada com um aspecto do estudo do movimento. Os pontos de partida são as leis de conservação, onde a conservação do momento linear leva ao conceito de força e assim para as leis de Newton; a conservação da energia leva ao conceito de trabalho e a seguir relaciona-se com o elemento força já definido; e a conservação do momento angular leva aos elementos rotacionais, como torque e aceleração angular. Nessa reconstrução, as três leis de conservação são os núcleos estruturantes da Mecânica.

Analisando os conceitos presentes nos mapas, verifica-se que a reconstrução 1 se restringe aos movimentos lineares; os vários "pontos de partida" para o tratamento conceitual e formal indicam uma Mecânica apresentada de forma fragmentada, pois não são articulados; a maioria dos elementos da teoria apresentados, com exceção da força, é articulada apenas por uma linha, indicando um tratamento sem profundidade formal e conceitual. A reconstrução 2, também com alguns "pontos de partida" isolados, apesar de incorporar novos elementos conceituais e formais à sua estruturação do conhecimento, os relaciona de forma artificial, pois também apresenta apenas uma linha articulando os conceitos. Na reconstrução 3, os elementos da teoria ganham outra dimensão pelas articulações que são estabelecidas entre eles, com um maior número de linhas indicando um tratamento conceitual e formal mais aprofundado; apesar de apresentar três "pontos de partida", como estes são relacionados entre si, a proposta não se configura fragmentada.

Assim, cada elemento de cada um dos três mapas é conceituado diferentemente pela maneira como estão identificados nas estruturas. Visualmente, o mapa 3 parece trazer uma mecânica mais complexa, pela presença de um número maior de elementos; no entanto, o maior número de linhas articulando esses elementos indica um tratamento conceitual melhor cuidado, com mais profundidade, portanto, simplificando o conhecimento à medida que o torna menos abstrato (MACHADO, 1999).

Em termos de ensino da Mecânica na educação média é possível inferir que, pelos livros didáticos indicados no PNLD/2011, existem propostas que 
levam a diferentes teorias da Mecânica, pois nessas reconstruções didáticas a compreensão de conhecimento científico também ganha significados diferentes. Quando o elemento estruturante é a força, o movimento a ser analisado vem como sua consequência, sendo primordial a força e não o movimento. Na situação em que a lei de conservação é o elemento estruturante, o movimento é o elemento que leva à identificação da força que o justifica. Nessa segunda perspectiva, fica implícita a visão de que existe uma realidade e de que existem leis que proíbem certos movimentos. Já na primeira proposição é possível estabelecer qualquer força e imprimir qualquer movimento, tenha ele realidade ou não.

Além da questão da realidade, também se identificam diferentes visões da Mecânica clássica embasando cada uma das reconstruções e até mesmo imagens distintas da ciência física perpassam as propostas. Por exemplo, Newton voltou seu olhar para o movimento e daí definiu o momento linear; suas leis dão conta da análise dos movimentos, fruto de interações entre corpos - a ciência cumprindo seu papel na proposição de modelos explicativos. Em seu trabalho, ele não define força, pois seu foco é outro. Quando o conceito central de uma proposta é o elemento força, há um reducionismo do trabalho de Newton, pois suas leis não estão no cerne das discussões e a análise do movimento se restringe à aplicação de $F=m a$, deixando de lado o modelo explicativo de que a taxa de variação do momento linear no tempo de um corpo implica a ação de uma força resultante sobre ele. Outra imagem equivocada da ciência parece estar presente quando as leis de conservação são pontos de chegada do tratamento conceitual-formal, pois, enquanto modelos explicativos, as leis de conservação definem as possibilidades dos movimentos existirem ou serem alterados, são causa e não consequência.

As considerações feitas sobre o conteúdo de Mecânica proposto pelos livros didáticos, suas articulações e visões implícitas merecem atenção principalmente se estes são indicadores dos conteúdos a serem trabalhados nas escolas e, portanto, o principal guia do trabalho docente. É importante notar que ensinar envolve fornecer elementos para que o estudante construa sua estrutura, ainda que inconscientemente. E essa nova estrutura erguida, tecida pelas relações estabelecidas com o conhecimento, é o que guiará sua leitura de mundo, traduzindo, assim, a qualidade de sua aprendizagem em Física.

\section{REFERÊNCIAS}

ALVES, R. Filosofia da Ciência: introdução ao jogo e suas regras. 10. ed. São Paulo: Brasiliense, 1994. 
APPLE, M. W. Trabalho docente e textos. Porto Alegre: Artes Médicas, 1995.

CHOPPIN, A. História dos livros e das edições didáticas: sobre o estado da arte. Educação e Pesquisa, São Paulo, v. 30, n. 3, p. 549-566, set./dez. 2004.

DELIZOICOV, D.; ANGOTTI, J. A.; PERNAMBUCO, M. M. Ensino de Ciências: fundamentos e métodos. São Paulo: Cortez, 2002.

FEYNMAN, R. P.; LEIGHTON, R. B.; SANDS, M. The Feynman Lectures on Physics - Volume I. Sixth printing. Massachusetts: Addison-Wesley Publishing Company, 1977.

GOETHE, J. W. A doutrina das cores. Apresentação, seleção e tradução de Marco Giannotti. São Paulo: Nova Alexandria, 1993.

GOODSON, E. F. Currículo: teoria e história. Petrópolis: Vozes, 1995.

KNELLER, G. F. Ciência como atividade humana. São Paulo: Zahar/Edusp, 1980.

LAJOLO, M. (Org.). Livro didático: um (quase) manual de usuário. Em Aberto, Brasília, v. 16, n. 69, jan./mar. 1996.

MACHADO, N. J. Epistemologia e Didática: as concepções de conhecimento e inteligência e a prática docente. 3. ed. São Paulo: Cortez, 1999.

NUSSENZVEIG, H. M. Curso de Física Básica - 1 - Mecânica. 1. reimp. São Paulo: Edgard Blücher Ltda., 1985.

OLIVEIRA, R. V. B. C. Formação continuada de professores e mudanças nas formas de estruturar a mecânica clássica. Dissertação (Mestrado em Ensino de Ciências, Modalidade Física) - IF-FE/USP, 1999.

PEREIRA, J. A. Uma reelaboração de conteúdo de Física do Segundo Grau: a eletricidade como exemplo. Dissertação (Mestrado em Ensino de Ciências, Modalidade Física) - IF-FE/USP, 1995.

PINTO, A. V. Ciência e existência. 3. ed. Rio de Janeiro: Paz e Terra, 1979.

POINCARÉ, H. O valor da ciência. Rio de Janeiro: Contraponto, 1995.

PREGNOLATTO, Y. H. A Eletrostática: o conhecimento possível e o conhecimento aprendido. Tese (Doutorado em Educação) - FEUSP, 1994.

ROBILOTTA, M. R. Construção e realidade no Ensino de Física. Textos para disciplina de curso de pós-graduação de mesmo título do Programa de Pós-Graduação Interunidades IF-FE/USP, 1994.

SALÉM, S. Estruturas conceituais no Ensino de Física: uma aplicação à Eletrostática. Dissertação (Mestrado em Ensino de Ciências, Modalidade Física) - IF-FE/USP, 1986.

Texto recebido em 20 de novembro de 2011.

Texto aprovado em 12 de dezembro de 2011. 